\title{
Entrevistando Joanne Entwistle...
}

Maria Claudia Bonadio ${ }^{9}$

https://orcid.org/0000-0001-9704-9780

Henrique Grimaldi Figueredo ${ }^{10}$

https://orcid.org/0000-0002-6324-4876

Rita Morais de Andrade ${ }^{11}$

https://orcid.org/0000-0002-1412-6689

Entrevista realizada no Hotel Holiday Inn, em Porto Alegre, no dia 31 de agosto de 2019.

\section{Como surgiu o interesse em estudar Sociologia da Moda?}

É uma pergunta muito boa. Meu interesse surgiu depois que terminei a minha graduação na Goldsmiths, em Comunicação e Sociologia, na qual tive a sorte de ser ensinada por Dick Hebdige, professor do Departamento de Comunicação e um dos fundadores dos Estudos Culturais na Grã-Bretanha. Era um ambiente intelectual muito empolgante e, quando eu saí da faculdade, sabia que queria continuar fazendo pesquisas. Tive a oportunidade de ler o livro de Elizabeth Wilson, Adorned in dreams, que, na época, era um dos poucos estudos existentes sobre moda. Esse livro não é apenas um texto histórico com lindas fotografias de roupas ou a biografia de um designer; é um texto que tenta discutir a emergência da moda, localizando-a em debates sobre modernidade e pós-modernidade, os quais eu estudava desde a minha graduação. Eu consumi o livro em um dia, fiquei muito empolgada e aquilo me fez pensar sobre as coisas que foram publicadas sobre moda e a maneira como as pessoas se vestem. Eu me fiz muitas, muitas perguntas. Naquele tempo, antes dos dias do Google, eu ia à biblioteca para tentar encontrar alguns livros sobre moda e havia, literalmente, quase nada; existiam apenas as histórias que focalizavam os detalhes dos traços e das cores ou biografias de designers sempre elogiosas, sobre Chanel ou algum outro nome. De fato, não havia nada

\footnotetext{
9 Doutora em História pela Universidade Estadual de Campinas (Unicamp). Professora Adjunta da Universidade Federal de Juiz de Fora (UFJF). mariacbonadio@uol.com.br. http://lattes.cnpq.br/3920027222039096.

${ }^{10}$ Doutorando em Sociologia na Universidade Estadual de Campinas (Unicamp). Mestre em Artes, Cultura e Linguagens pela Universidade Federal de Juiz de Fora (UFJF). henriquegrimaldi@hotmail.com. http:// lattes.cnpq.br/8304774973046394.

${ }^{11}$ Doutora em História Cultural pela Pontifícia Universidade Católica de São Paulo (PUC-SP). Professora associada da Universidade Federal de Goiás. ritaandrade@ufg.br. http://lattes.cnpq.br/0652175469093010.
} 
que explorasse realmente o significado do vestuário na vida cotidiana, como as pessoas se vestem. E foi aí que comecei a pensar: por que não existe uma sociologia do vestuário, nem mesmo nos estudos sobre subculturas? Quando estudávamos aspectos do vestir, era sempre um vestir espetacular, eram os mods e os punks, os roqueiros, os góticos, as comunidades espetaculares que fazem coisas espetaculares com suas roupas, coisas que havia visto nas minhas aulas sobre teoria das subculturas (com Dick Hebdige) e o relato clássico da subcultura, esse tipo de tradição. 0 que me interessava era: o que nós fazemos com o vestir ?; onde estão os relatos da experiência diária das pessoas em se vestir? Como socióloga, eu me interessava em pensar o vestir como parte essencial da ordem social: a menos que você seja um nudista - uma pequena porcentagem da população vive sem roupas -, o restante de nós precisa vestir-se, faz parte do relato diário do mundo social e da ordem social e, novamente, havia uma ausência dessa dimensão de pesquisa. Explorando esse assunto na perspectiva de 2019, parece extraordinário que não tivessem textos naquela época. Havia alguns trabalhos na Antropologia, pessoas explorando o vestir cotidiano de Papua Nova Guiné, por exemplo; havia algumas [... $]^{12}$ antropologias do vestuário, do quimono, das roupas tradicionais indianas. Entretanto, onde estavam os estudos sobre o vestuário ocidental? 0 vestir diário, não a maneira espetacular de se vestir, mas o vestir comum? Decidi fazer o meu doutorado nessa área e, visto a escassez da produção no campo, tive que escolher um tipo de experiência de vestuário para estudar, estreitar esse mundo em alguns aspectos. Então, decidi escolher o power dressing e estudar mulheres vestidas para o trabalho, o mundo da carreira, porque parecia um tipo muito específico de se vestir, no qual eu imaginava que existia alguma consciência dos sujeitos em suas escolhas. Isto é mais potente do que perguntar às pessoas portando um terno atraente como elas se vestem. Eu escolhi um estilo do vestir que se inseria em um debate: na época, as pessoas estavam falando sobre a mulher e suas carreiras, o que significava ser uma mulher no mundo do trabalho, em um traje de poder. Por isso, elegi um estudo de caso específico para explorar os debates sobre esse corpo vestido.

A Goldsmiths College, instituição pela qual obteve seu título de doutorado em Sociologia, em 1997, havia sido, no fim dos anos 1980 e no início dos 1990, o celeiro criativo que produziu uma das gerações mais inventivas da arte contemporânea britânica. Desde Freeze, em 1988, artistas como Damien Hirst e Angela Bulloch, sob a égide do novo ensino de Michael Craig-Martin, transformaram-se em fenômenos mundiais. Ao mesmo tempo, uma nova geração de estilistas, como Alexander McQueen, John Galliano e Andrew Groves, formavam-se na Central Saint Martins. Como você enxerga as relações entre a produção estética do período na arte e na moda e como foi estar inserida academicamente nesse contexto, em uma fase de claras mudanças nos modos de produção da cultura britânica e mundial?

\footnotetext{
12 Usaremos a reticência como recurso para representar passagens de áudio incompreensíveis. Esses trechos, editados com permissão da autora, não representam perda de conteúdo nas respostas fornecidas.
} 
Grande questão: é muito empolgante refletir sobre o meu período na Goldsmiths. Eu era uma Goldsmiths [...], então, eu estava lá naquele período realmente emocionante; a Freeze [a exposição] e tudo o mais ocorreram no momento que eu estava na graduação. Eu vi essa exposição várias vezes, foi enorme [...]. Foi uma ótima época para ser uma Goldsmiths e, mais tarde, muito depois, minha carreira levou-me a um emprego na London College of Fashion, que faz parte da University of the Arts e está conectada a alguns estudantes e pesquisadores da Central Saint Martins (CSM). Eu tive uma jornada entre esses dois mundos, uma formação que, apesar de não ser na área de artes - mas, como uma aluna da Goldsmiths -, levou-me a experimentar esse tipo de criatividade que há em Londres, e também a experiência de cursar uma faculdade de Moda londrina. Há uma grande história e uma tradição na Academia Britânica no brincar com as fronteiras entre arte e cultura popular, traços advindos da pop art, de um chiste [...], e assim por diante. Isto era, claramente, o tipo de coisa que estava acontecendo na Goldsmiths à época: a continuidade de uma forte tradição de irreverência na arte. Era o tipo de faculdade de Arte que instigava certo divertimento, certa insolência, o ser crítico e o brincar com as fronteiras entre a alta e a baixa cultura. Fazia parte daquela tradição, daquele mundo, nessas faculdades - como Goldsmiths e a CSM -, artistas flertarem com o que era considerado baixa cultura, estilistas misturarem muitas coisas diferentes, como McQueen, apenas para testar coisas diversas. É por causa dessa tradição das faculdades de Arte que, penso eu, Londres é conhecida como um centro criativo, um lugar no qual designers de moda propõem ideias colaborativas e irreverentes. Essa é a diferença entre a tradição do nosso treinamento e os outros treinamentos em Moda - como Milão, Nova York ou Paris -, onde as coisas podem ser mais técnicas, com uma mão de obra mais especializada, e negociações (em Milão ou em Nova York) que transformam esses espaços em locais muito comerciais. Londres é esse tipo de celeiro criativo. Mais tarde, quando acontecem o pop britânico e a Cool Britannia, ou mesmo a política governamental dos anos 1970, estimula-se um senso de britishness (uma forma britânica única de criar e de pensar). Foi uma época fantástica para estudar moda porque eu saí das tradições e pude pensar na moda e nas artes comunicando-se, pude mover-me entre essas diferentes práticas. É isso que torna a Grã-Bretanha famosa, especialmente a CSM, um local vibrante para estudar moda. Então, como foi? Foi fantástico! Muito divertido! Eu acho que, embora meu trabalho nunca tenha realmente tratado de arte, sou mesmo uma socióloga da moda. É impossível se afastar da tradição de ser irreverente, do tipo de criatividade que faz parte do estudos em arte e dos estudos em moda nas universidades inglesas.

Você contribuiu com textos e pesquisas para a plataforma Showstudio, de Nick Knight, um dos fotógrafos britânicos mais experimentais do campo da moda e o responsável pela primeira transmissão ao vivo de um desfile (Plato's Atlantis, de Alexander McQueen, em 2010). Em 2002, embarcou em um projeto de larga escala, designado pelo Economic and Social Research Council (ESRC), para examinar o trabalho de compra de moda no setor varejista no Reino Unido. São atuações em escalas bastante distintas: a primeira em um campo mais experimental e subjetivo, 
outra com uma abordagem oficializada e objetiva. Gostaria que você, por gentileza, falasse um pouco de ambas as experiências e como elas impactaram o seu ofício como socióloga e pesquisadora do campo da moda?

Até onde eu sei, só colaborei uma vez. Foi uma pequena colaboração. Eles me pediram para escrever um ensaio sobre body size. Nick Knight explora esses aspectos da moda, ele critica o tipo de estética magra. Essa colaboração foi a convite de Penny Martin: ela me convidou quando era time curator, isto é, na ocasião, era a segunda no comando, depois de Nick Knight (o fotógrafo). Foi fantástico, mesmo que eles nunca tenham me convidado para outra colaboração (risos). Ocasionalmente, faço ensaios mais populares sobre o corpo e a moda. Recentemente, colaborei com o Days Beauty, uma iniciativa de Jefferson Hack: eles me convidaram para comentar essas questões com duas outras estudiosas da moda. Elizabeth Wilson era uma delas [...]. Então, contribuí nesse ensaio que foi publicado há alguns meses no Days Beauty. Eu faço esse tipo de coisa. Sempre me empolgo escrevendo com um estilo mais popular, para comunicar algumas ideias teóricas para um tipo diferente de público. Esses são alguns exemplos de colaboração que tenho feito, não tenho muito mais a dizer sobre isso, exceto que esses textos são também interessantes de se fazer. Foi um desafio pensar de maneira diferente, escrever de um jeito mais acessível. No entanto, onde me localizo de forma mais sólida é na Sociologia, e na abordagem empírica para entender a moda. O projeto sobre fashion buyers, da ESRC, surgiu do meu interesse em ver quem são os mediadores, quem são as pessoas que tomam decisões sobre a moda. Como atuam nos bastidores? Como Nick Knight e Kate Moss, você tem um grupo inteiro de agentes com nomes e rostos que reconhece imediatamente quando pensa na indústria da moda: eles são a face pública da moda, os grandes nomes criativos. Contudo, como socióloga da moda, sei que há todo um sistema de produção e consumo, há uma rede de mediação que produz o que chegou às lojas e o que é compreendido como moda. Eu estava interessada em explorar esses agentes que ficam nas sombras, pessoas poderosas, pessoas desconhecidas, que habitam os bastidores - e foi isso que me levou a fazer uma inscrição no Standard Occupational Classification (SOC). Quando solicitei o empréstimo, eles nunca haviam financiado nada na área da moda; a moda sempre teve esse status baixo na academia, embora isso esteja mudando há algum tempo. Eu acho que era 2001 quando me inscrevi, e as pessoas diziam: "Você não receberá dinheiro porque eles nunca financiarão algo como moda". Mas eu consegui o financiamento e foi fantástico. Isso nos mostra a mudança na maneira como a moda vem sendo valorizada. Ou seja, naquela ocasião, era a coisa mais séria para se estudar, e fui patrocinada por um fundo governamental [...]. Eu me propus a estudar especificamente a mediação de roupas da moda, o trabalho que os compradores tinham para mediar; eu estava estudando a maneira como eles encaravam os negócios e como procuravam os designers em seus estúdios, como faziam escolhas e seleções sobre o que comprar para as lojas e como eles entendiam o consumidor. Quando pensava no processo de mediação do produtor, dos designers e do consumidor, precisava olhar para os dois lados: era realmente o que aguçava a minha curiosidade. Esse projeto concentra-se na investigação sobre quem são os mediadores, esses indivíduos que tomam as decisões, e onde eles estão localizados. Observei também o 
trabalho da mediação: como as roupas da moda eram mediadas?; como era feita a mediação do pensamento sobre os cálculos da moda?; o que estava realmente acontecendo?; como as coisas chegam às lojas?; como ocorre a mediação contínua desses bens?. Essa é apenas uma maneira de entender esse trabalho. 0 importante [...] trabalho de criação de valor da moda é feito por essas pessoas e elas estão todas nos bastidores; foi realmente uma direção lógica para seguir depois de estudar os corpos na maneira como o vestir funciona (em The fashioned body). Como essas pessoas escolhem as roupas? As escolhas são predeterminadas por um grupo, quais são as implicações disso? [...].

No seu livro The fashioned body, publicado em 2000, você faz uma crítica aos estudos sobre moda, pois, de modo geral, até aquele momento, a maior parte dos trabalhos nos quais teóricos e sociológos tratavam de moda não se preocupava em pensar a relação intrínseca entre corpo e moda, ocupando-se mais em relacionar moda ao consumo, ao texto, escrito ou imagem, por exemplo. Passados quase 20 anos da publicação do trabalho, o que você acha que mudou na produção científica sobre moda, no que diz respeito a esse tema? A relação entre corpo e moda? Quais são os impactos dos crescentes estudos sobre gênero nos fashion studies e, especificamente, nos estudos que relacionam corpo e moda? Além da influência dos estudos sobre gênero, que outros temas correlatos têm impactado nos estudos sobre corpo e moda produzidos contemporaneamente?

Desde a publicação de The fashioned body, lentamente no começo, mas acho que acelerando nos últimos 10 anos, vemos uma explosão de trabalhos nessa área. Seria impossível dizer que ninguém focaliza mais a moda e o corpo, porque todos o fazem. Os pesquisadores que trabalham nessa área estão fazendo várias coisas com esses temas e há livros que exploram muitos, muitos aspectos diferentes de diversas práticas de vestuário, além disso, muitos trabalhos estão pensando no embodiement ${ }^{13}$, na moda e no corpo vestido. Eu acho que essa é uma das maiores mudanças, simplesmente é a progressão do conhecimento [...]. Se você olhar o catálogo da Berg, uma das principais editoras do Reino Unido - eles publicaram o meu segundo livro, Body dressing -, há um crescimento substancial desses estudos [...]; é um catálogo enorme de trabalhos nessa área discutindo aspectos muito diferentes. 0 gênero tem sido bastante crítico nessa agenda temática em torno do corpo e do mundo das roupas. Isso tem uma influência enorme; quero dizer, os estudos de moda são multidisciplinares, mas, definitivamente, os estudos feministas e os de gênero têm sido bastante críticos no crescimento dos trabalhos nessa área. Obviamente, as pesquisas caminham para além disso. Uma das alterações mais

\footnotetext{
${ }^{13}$ Escolhemos não traduzir o termo para uma melhor compreensão de seus alcances e suas nuances. A manutenção da terminologia original visa garantir uma estabilização do conceito e sua não concorrência com outros termos como corporificação, que pode assumir significados outros.
} 
sensíveis nesse campo advém dos estudos realizados com transgêneros, na teoria queer, que provocaram um desenvolvimento maciço ao explorar enfaticamente a maneira que o mundo da moda atua sobre o corpo. Portanto, eu diria que os estudos queer - particularmente, os temas transgêneros e pós-gêneros - têm representado uma grande chave temática dessas pesquisas, contudo, há também questões outras surgindo. Há outros trabalhos sobre moda e sustentabilidade que, na minha opinião, estão prestes a expandir os debates em termos de mudança climática e emergência climática. Há outras agendas que estão moldando o futuro da moda, para além dos financiamentos e dos estudos que moldaram sua fase inicial [...]. Além disso, outro tema que eclode são as geografias da moda em um sistema global que compreende as conexões, a globalização da moda de forma sistemática. Você não entende a moda contemporânea sem isso, ou seja, vocês sabem como é [o sistema da moda] no Brasil, eu não sei muito sobre os estudos da América Latina sobre moda, peço desculpas! Mas, na Europa, as ruas estão repletas de cadeias de fast-fashion, você não pode estar no mundo dos estudos de moda sem questionar o que representa essa modalidade de moda. Como ignorar o que chega às lojas da Zara? Tivemos uma mudança maciça na indústria da moda, que se desloca ao redor do mundo, os materiais e a costura das roupas que circulam por muitos países antes de chegarem às lojas propriamente ditas. Portanto, pesquisas na área da geografia são muito importantes para levantar questões sobre os movimentos e as trilhas globais da moda, um movimento físico real das mercadorias. Claramente, isso também tem sido uma peça importante nos debates sobre sustentabilidade, ou seja, tudo o que é produzido está causando impacto, essa é uma grande questão nos estudos contemporâneos. Outro tema que podemos elencar é o desenvolvimento de espaços alternativos de moda, que escapam às revistas. Coisas construídas nas mídias sociais, por exemplo. 0 crescimento das mídias sociais, inicialmente dos blogs e depois do Instagram, é algo extremamente significativo e que tensiona o que costumava ser compreendido como moda e o que era considerado um corpo da moda. Essa alteração atrapalha a mediação dos líderes [e da elite] de moda, que atuam em revistas específicas, como fotógrafos, estilistas e designers, escolhendo tipos específicos de corpos, modelos magros e jovens que ainda surgem nas campanhas das revistas. As mídias sociais realmente mudaram o controle desse aspecto, provocando um desafio para esse sistema. Agora, as pessoas podem estar no Instagram e isso realmente mudou o controle do que é estética, desafiou a elite da moda. Nesse sentido, as pessoas podem ser seus próprios modelos, estilistas, editores de moda, com/no seu blog ou Instagram. Logo, esse é outro tópico em desenvolvimento nos estudos de moda, e que coloca uma direção que desejo seguir no meu novo trabalho, explorar a moda - comum - no Instagram. Não é um espaço totalmente liberado dos líderes de moda que controlam sua estética e representação. Eles claramente ainda estão lá, mas foram desafiados pelas imagens de comunidades de moda alternativas, que agora têm a capacidade de promover suas ideias, seus corpos que fogem de um ideal branco-jovem-magro. Nesses espaços, podemos encontrar um tipo diferente de corpo, e existem muitas comunidades de blogueiros/instagrammers que promovem essa estética alternativa [...]. 0 poder disso é uma ruptura com uma visão de moda anteriormente estreitada. Quando você possui apenas a mídia impressa, este se torna o único caminho para se obter uma ideia de moda - a centralida- 
de da Vogue, por exemplo. Agora, você não precisa mais dessas ferramentas e é por isso que as revistas de moda estão entrando em colapso, as pessoas vão ao Instagram para ver moda. Em suma, acho que essa é outra área para a qual os estudos de moda estão caminhando: muito na direção dos estudos de mídia e comunicação [...].

Você poderia nos contar sobre o projeto Body dressing em parceria com a professora Elizabeth Wilson? Quais são as principais questões que nortearam a edição da publicação? Além disso, de que perspectivas podemos pensar as noções contemporâneas de embodiement?

Eu tive alguns problemas para responder esta questão (risos) porque faz muito tempo e eu não lembro exatamente o que aconteceu. Primeiro, quero explicar o contexto do livro: logo depois do meu doutorado, eu consegui um emprego na atualmente chamada London Metropolitan University, no mesmo departamento que Elizabeth Wilson. Éramos duas das principais pesquisadoras de moda no Reino Unido, logo fazia sentido desenvolvermos um projeto juntas. Assim, eu coordenei os temas, pois desejava que fosse um estudo sobre moda e embodiement. Contudo, havia, claramente, um componente histórico: o livro tem muitos textos históricos que conversam diretamente com os interesses de Elizabeth sobre história da moda. [Body dressing] foi uma edição de textos e pesquisas e demorou muito tempo para ser elaborada, deu muito trabalho, representou a maneira de consolidarmos um conjunto de interesses sobre moda, de iniciar um diálogo sobre o assunto. Criamos, assim, um projeto conjunto que estipulava uma declaração sobre o embodiement na moda. A questão que organiza o livro foi dividida em três partes. Nelas, existiam preocupações teóricas e com os debates emergentes sobre diferentes momentos da história. Começamos a pensar em conexões sobre o vestir e o corpo em vez de apenas pensarmos sobre o fenômeno do vestir a partir dos tecidos e de quais estilos de vestuário que poderiam ser vendidos em determinado momento. Vimos esses temas articulando-se com o corpo e o seu momento na história, induzindo as pessoas a conectarem suas práticas corporais. Novamente, foi um livro de afirmação sobre o papel do corpo e o embodiement na moda - ao trabalharmos com as roupas, é importante conectar essas dimensões. Ainda acho que é um dos primeiros livros que realmente fez uma declaração. Sobre as noções contemporâneas de embodiement, reluto um pouco diante disso [...]. Os debates sobre embodiement vieram de uma tradição fenomenológica que estudei na Goldsmiths para o meu doutorado. Minha orientadora foi Helen Thomas e ela era uma especialista em dança, não uma especialista em moda, mas muito do seu trabalho em dança parte dessa inflexão fenomenológica. 0 que fiz foi desenvolver algumas ideias sobre fenomenologia que contemplassem a experiência de ser um corpo. Agora, para a sua pergunta: onde podemos encontrar noções e debates contemporâneos sobre isso? Honestamente, eu não me sinto qualificada para dizer. A concepção que precisamos ter em mente é a de um corpo como um tipo de representação da plenitude e do embodiement como experiência; a experiência de ser um corpo. Existem estudos fenomenológicos que falam sobre experiências de embodiement do vestuário. Tornou-se parte da linguagem dos estudos 
de moda, mas não posso indicar efetivamente nenhum nome. Parei de trabalhar com essa dimensão porque fiz meu estudo para a SOC e estava mais preocupada com o problema da indústria. Eu não sei exatamente, mas penso que há um senso bastante estabelecido no qual podemos falar sobre o corpo como uma imagem de representação ou ainda experiências dos corpos. Pessoas como Nick Crossley [...] estão desenvolvendo pesquisas sobre esses temas. Muito trabalho foi feito sobre isso, mas não consigo pensar em nenhum nome no momento.

Um aspecto da sua pesquisa que chama nossa atenção é o interesse pelos valores estéticos da moda e a maneira como ela se relaciona com as agendas culturais e também econômicas. Particularmente em seu livro The fashioned body: fashion, dress and modern social theory (2. ed., 2015), você menciona alguns desenvolvimentos recentes sobre teoria da moda e as tentativas do campo de ampliar o conceito de moda a modelos econômicos fora do mundo ocidental moderno. Como pesquisadores trabalhando no Brasil, e considerando nossa complexa experiência histórica da colonização europeia, você pode compartilhar sua perspectiva de como abordar as formas de vestir o corpo como uma prática além de modelos econômicos específicos, como o que consolidou as imagens de um sistema global de moda?

Quando escrevi The fashioned body, essa era/é a parte mais fraca do meu livro [os debates pós-coloniais]. Eu sou uma socióloga, uma socióloga europeia, e o meu ponto de partida foi - como era também o de Elizabeth Wilson - os significados da modernidade. Parti da perspectiva de uma modernidade europeia. Certamente, existem outras modernidades e houve um volume maior de trabalhos sobre a modernidade ocidental. A modernidade ocidental europeia é uma modernidade, não é $a$ modernidade. Acho que grande parte do trabalho recentemente produzido na Antropologia e nos estudos de Moda caminha no sentido de um reconhecimento dos cruzamentos possíveis entre diferentes tipos de modernidade, diferentes velocidades da modernidade. A modernidade na América Latina é diferente da modernidade na Índia e da modernidade na Europa. Penso, no caso do livro, que eu não possuía uma formação antropológica e me localizava a partir de uma narrativa muito específica, mas tenho consciência de que não é a única narrativa [...]. Acho que na segunda edição, eu falei um pouco sobre isso na introdução, no prefácio: fiz um alerta para pensarmos mais amplamente sobre a modernidade. Claramente, há muitas diferenças em relação à moda ao redor do mundo, ideias de moda, materiais, vestuário, tecidos e assim por diante. Há também um entrecruzamento político e muito material sobre essas diferentes modernidades. Casas de moda em Paris, em Londres enviam desenhos para fábricas em Bangladesh, nas quais pessoas pobres costuram as roupas, que depois retornam para vestir uma ideia de ocidentalidade moderna. Estamos lidando com um entendimento sobre o que significa(ou) a colonização europeia e o que significa o capitalismo, estes provocam ciclos de produção. Por que essa produção está alocada em uma fábrica em Bangladesh e não em outro lugar? Claramente, estamos falando sobre pessoas para quem o vestir e a costura não têm relação 
com eles mesmos. Então, quem são esses sujeitos e quais são as suas condições de trabalho? Esses indivíduos são invisibilizados. No entanto, são afetados pelas condições ruins das cadeias de produção. Há diferentes modernidades colidindo-se imediatamente naquela fábrica: além da condição de costurar roupas para os consumidores ocidentais, ainda em Bangladesh, há uma cadeia econômica na qual essa fábrica é importante na modernidade da cidade. A moda sempre foi o centro de muitas economias em desenvolvimento. Foi o motor da Revolução Industrial. A produção de algodão, em Lancashire, foi um dos impulsionadores da revolução industrial britânica e isso dependeu da colonização, foi uma produção que veio com as colônias. A história da moda é a história de diferentes modernidades, diferentes formas de modernização, e agora na Índia, em Bangladesh, a moda novamente está no centro de muitos dos desenvolvimentos econômicos, é o modo como algumas economias estão saindo de uma perspectiva agrícola para uma economia industrial mais moderna; portanto, essas relações são importantes em Bangladesh, na Índia, na Turquia e em muitos outros lugares. Não conheço o Brasil e a América Latina, peço desculpas, mas é claro que precisamos pensar nas muitas interações complexas entre essas diferentes modernidades nos níveis temporal e geográfico. Esse é o sentido com o qual, na verdade, muitos trabalhos foram produzidos. Na geografia, essa ideia é bastante útil. Os estudos de moda surgiram da geografia e isto nos coloca uma forma de pensar: há uma história complexa sobre a modernidade e a colonização. Acho que as ex-colônias ocidentais agora reconhecem, assim como eu reconheço, que precisamos olhar para trás, para as modernidades complexas. Como parte dessas narrativas, como parte dessas diferentes modernidades, nesses outros países, na Índia, no Brasil, em todo o mundo, podemos pensar o surgimento das fashions weeks, das diferentes capitais da moda. Logo, outra parte do desenvolvimento de diferentes discursos da moda (e da modernidade da moda), e de diferentes tipos de sistemas de moda, encontra-se na ideia da fashion week. Eu tive uma colega que trabalhou muito nessa área. Ela era pesquisadora na London College of Fashion quando eu ministrava aulas lá. Sua pesquisa tentava mapear as diferentes capitais da moda - sabemos que agora existem muitas -, e quando ela exibiu alguns dos resultados, anos atrás, contabilizou uma centena de semanas de moda. Provavelmente, existe uma fashion week no Rio e outra em São Paulo. Isso provoca perguntas muito boas sobre o que significa ser uma capital da moda, o que significa ter uma semana de moda. De algum jeito, é uma maneira de se inserir na velha tradição que começou nas big four: Londres, Nova York, Paris e Milão. Inserir-se como capital da moda é, em parte, inserir-se no sistema estabelecido, em uma narrativa estabelecida, uma narrativa também política. Isso é importante: toda cidade grande precisa falar sobre isso globalmente e, dessa maneira, promover suas indústrias da moda. Enquanto muitas dessas capitais da moda estão desafiando as quatro grandes potências, estas ainda se firmam como os únicos espaços de confiabilidade em relação às tendências da estação. De fato, as big four ainda são poderosas. Se você perguntar às pessoas o que é uma semana de moda ou o que é uma capital da moda, provavelmente, elas responderão com esses quatro lugares (Paris, Londres, Nova York e Milão). Esse é um debate interessante: quais narrativas sobre moda e suas capitais ainda são elaborados. Isso expressa a manutenção de um antigo poder colonial, se pensarmos o poder da moda mundial. Há um conjunto interessante de questões. Eu quero fazer um projeto sobre 
semanas de moda e capitais da moda, mas atenta aos centros diferentes, escolhendo outros lugares, países do Hemisfério Sul. É um projeto para ser desenvolvido no futuro.

Sobre moda e identidade, você argumentou que o que as roupas dizem sobre o usuário é algo que não é muito mais que um clichê, pois há outras camadas a serem consideradas nessa relação. Contudo, essa identidade continua sendo um dos tópicos mais presentes nos estudos de moda. Você poderia falar um pouco mais sobre moda e identidade e dizer por que isso se torna um desafio para o campo nos últimos anos?

Eu gosto dessa pergunta. Fico realmente frustrada quando as pessoas levantam acepções simplistas sobre a moda e as identidades, particularmente sobre a moda e certas identidades. Falo sobre essa questão puramente como socióloga: os indivíduos só assumem esse tipo de poder para produzir declarações - fashion statements - porque nasceram dentro de comunidades e de complexas relações sociais, portanto, há um tipo de abordagem sociológica que sempre irá olhar para os locais onde os sujeitos estão situados. 0 foco na identidade torna-se problemático quando pensamos que o indivíduo pode falar apenas por meio da roupa. Isso é impossível. As roupas são claramente comunicativas, elas vão nos dizer algo sobre os sujeitos. Há muitos estudos iniciais sobre moda como fenômeno de comunicação e linguagem, como, por exemplo, os trabalhos de Alison Lurie e Malcolm Barnard. Muitas pessoas tentam explorar a maneira como a moda se comunica, mas nunca será simples, porque, como indivíduos, não temos esse tipo de liberdade e as roupas não falam livremente. Elas falam sobre o contexto social. Elas falam sobre situações complexas, localidades ou tradição de classes; logo, cada situação ou cada entrada possui diferentes regras e códigos [...]. Quando nós nos vestimos, mesmo que não o façamos conscientemente, estamos nos preparando para uma situação, ou melhor, para uma situação social. Parece haver certa liberdade nisso; um biquíni é uma peça de vestuário perfeita para a praia, entretanto, não a usamos no trabalho, logo, não há uma completa liberdade no vestir-se. "Serei eu mesmo e falarei livremente por meio da moda!" Claro que não! Nós nos vestimos para uma situação especificamente, assim, a situação e a roupa que você usa para ela nos dizem algo sobre seu contexto. Essa foi a razão para que eu elegesse, no meu primeiro estudo, formas empoderadoras de se vestir. Eu escolhi essa coisa real porque estava interessada em uma situação na qual existe um contexto bastante claro, e como as pessoas preparavam seu corpo para aquele contexto. Assim, cada contexto que adentramos, coloca-nos uma questão sobre o que devemos vestir. Raramente, veremos alguém com traje de banho sentado em um escritório, a não ser que seja um designer em uma companhia que produz trajes de banho, onde será apropriado e aceito o uso de shorts no ambiente de trabalho, mas, novamente, isso ocorre apenas por causa do contexto dessa situação especificamente. Portanto, como socióloga, essa é minha perspectiva: com base sempre em onde as pessoas estão localizadas, onde o vestuário também está situado, é necessário pensar quais são os códigos e as regras para essa situação e, em seguida, como o vestuário se manifestará simultaneamente naquele contexto e nas escolhas individuais das pessoas. Obviamente, nos códigos, existem 
convenções de situações nas quais o sujeito assume alguma liberdade, pode fazer algumas escolhas, mas elas sempre serão delineadas pelo contexto posto. Outra questão é se a identidade é complexa no agenciamento de diversas coisas. Nossa identidade está continuamente em processo, então, sim, nosso vestuário está sempre envolvido com a nossa identidade, nós nos movemos e transitamos por realidades diversas. Há diferentes formações de identidade nas crianças ou em estudantes, para quem seria apropriado usar certas coisas, mas, no local de trabalho, a escolha pelo o que usar será outra. Portanto, nossa identidade é fluida, e essa é a outra forma que a modernidade instaura para apreendermos tais fenômenos, sempre articulando alguma expressão individual. Todo tipo de trajetória de vida é a expressão de diferentes partes de nós mesmos, um tipo muito próprio de evolução temporal, se você preferir. Dito isso, há momentos e lugares nos quais podemos nos sentir muito livres e capazes de expressar nossa identidade, e é por isso que as dinâmicas subculturais foram tanto pesquisadas e escritas; nelas, as pessoas geralmente são jovens e têm um breve momento de liberdade diante de diferentes restrições, ou mesmo que não tenham liberdade quando estão trabalhando em um escritório, por exemplo, nos fins de semana, vestem outras roupas e se sentem expressando seu verdadeiro eu. Seu verdadeiro eu porque se identificam com uma subcultura específica. A roupa que irão vestir realmente articula uma identidade muito forte, mas é uma identidade de uma subcultura, é uma faceta da sua participação em uma subcultura. Entretanto, mesmo no mundo da teoria da subcultura, os limites são agora muito fluidos, e ainda como membros de algumas subculturas, esses sujeitos provavelmente ainda terão que seguir certos códigos e regras, e podem, inclusive, na segunda-feira de manhã, vestir um terno e esconder as tatuagens, caso estas sejam consideradas inapropriadas nos seus locais de trabalho. Existem várias maneiras pelas quais podemos perceber declarações muito claras sobre a identidade, mas, mesmo assim, existem acordos sociais que são exigidos como mecanismo de pertença a uma subcultura ou a um grupo. E a moda faz isso de maneira exemplar: ela articula identidades e grupos de forma muito coerente. Mesmo que, ao olhar a roupa de uma pessoa, você possa conhecer algo sobre a sua identidade individual, penso que o vestir é limitado para compreendermos a sua complexidade, às vezes nos diz apenas "isto é o que esta pessoa está usando hoje". Nosso relacionamento com as roupas é complexo e precisamos trazer algum tipo de conhecimento sociológico sobre as situações de contexto. Os diálogos individuais precisam ter um contexto social; nesse ponto, Simmel é muito útil para explicar como nós, como indivíduos, temos que nos encaixar em um grupo social, as negociações que precisam ser feitas entre os indivíduos e o social.

No Brasil, além das obras "clássicas", como os textos de Veblen, Simmel e Barthes, por exemplo, produções mais recentes, como a obra de Elizabeth Wilson Adorned in dreams (Enfeitada de Sonhos) e The empire of fashion: dressing modern democracy ( 0 Imério do Efêmero: a moda e seu destino nas sociedades modernas), de Gilles Lipovetsky (ambos traduzidos para o português), são referências importantes para os estudos de moda. No entanto, no trabalho de pesquisadores britânicos, 0 filósofo francês não parece ser uma referência tão importante. Por que 
você acha que o trabalho de Lipovetsky, mesmo traduzido para várias línguas, não produz ressonâncias na Grã-Bretanha?

O trabalho de Lipovetsky foi publicado no fim do meu doutorado e, naquele momento, eu estava bastante localizada nas discussões de cunho sociológico. Então, quando vi o seu trabalho, logo pensei: "Isso é relevante?". De certa forma, fiquei frustrada e continuo frustrada com as afirmações excessivamente teóricas sobre moda. Elas não são baseadas em evidências empíricas. Elas não se baseiam em nenhum tipo de encontro empírico. Posso estar sendo hipócrita em alguma medida, pois eu uso as ideias de Veblen, Simmel e Barthes; acho que Barthes utiliza algum material empírico, mas, de fato, alguns desses pensadores estavam apenas escrevendo teorias sem fundamentos empíricos. No entanto, quando olho para o trabalho de Lipovetsky, eu logo penso: "Temos um filósofo sentado em uma poltrona escrevendo acepções sobre moda". E sim, talvez ele tenha feito alguma pesquisa empírica. Acho que o meu trabalho caminha no sentido contrário dessa tradição, eu queria fazer um estudo sociológico que analisasse o que as pessoas fazem, o que dizem sobre o que fazem, observar o que as pessoas fazem com os seus trajes, em vez de ler sobre os pensamentos de um filósofos sobre trajes; essa é a razão pela qual eu tendo a não utilizá-lo. Eu acho que o livro The fashioned body foi muito importante, mas, nele, eu realmente não o citei. Não sei se sou o motivo pelo qual Lipovetsky não tem muita entrada no Reino Unido. Talvez, outros estudiosos da Grã-Bretanha sintam uma frustração semelhante à minha. Esse não é o tipo de estudo abordado no The fashioned body, nem o tipo de estudo que surgiu após a publicação do livro. Nos estudos posteriores ao livro, as pessoas saíram e entrevistaram as subculturas, observaram o que as pessoas faziam com as roupas. São outros tipos de trabalho, como o de Sophie Woodward, uma antropóloga que se sentava nos quartos das pessoas, abria seus armários, olhava o que elas estavam vestindo, como elas faziam para usar aquelas roupas, quais eram as considerações e os cálculos envolvidos no vestir-se. Para mim, isso é mais valioso do que ler um filósofo pontificando sobre a moda. Não dou muito valor para isso. Eu me sinto frustrada. Como você conhece as pessoas? Como elas querem expressar a sua liberdade e a sua identidade, como você sabe? Prove para mim! Eu acho que, no Reino Unido, existe uma forte tradição empírica, enquanto na França há uma tradição filosófica mais latente. Eu simplesmente acho que, dessa maneira, somos incapazes de traduzir bem as relações; acho que esta é, provavelmente, a razão pela qual há as tradições na academia, tradições nacionais, e tenho o prazer de dizer que no Reino Unido, geralmente, tentamos sair e perguntar às pessoas, e observamos o que as pessoas fazem quando se vestem, em vez de ficarmos tecendo teorias sobre isso.

Em The aesthetic economy of fashion, você define um mercado estetizado como aquele no qual a qualidade estética, seja uma aparência ou um estilo, encontra-se mercantilizada, isto é, definida e calculada como um mercado em si e vendida visando lucro. Assim, "onde estética não é algo adicionado como uma firula decorativa que se encontra além da definição do produto", nesses mercados, "a estética é o produto, 
tornando-se central nos cálculos econômicos desta prática"14. Nesse sentido, há certa hibridação dessas estruturas, temos que compreendê-las também como econômicas e não mais como meramente cultura ou estética. Quais são as alterações substanciais desse conceito na tradição sociológica, de Simmel a Featherstone, por exemplo? Há outras alterações sensíveis nesses mercados que possam ser hoje detectadas, passados dez anos da sua primeira publicação?

Existem muitos trabalhos sobre essa dimensão. Simmel e Featherstone talvez façam parte disso, mas existem muitos estudos no Reino Unido sobre a compreensão do papel dos produtos estéticos, mercados, serviços e economia. Não é necessariamente sobre moda, mas sobre o papel que a estética - bens e serviços - agora desempenha nas economias ocidentais. Existem grandes debates sobre o valor do papel da cultura na economia e na economia estética. Meu livro tenta descrever esses desenvolvimentos e mostrar como o mercado capitalista, no contexto de um capitalismo tardio, realmente depende desses produtos e não, apenas e somente, da indústria pesada. Certamente, a indústria pesada é importante [...]. É um fato empírico: algo que acontece nos últimos anos, em parte por meio do pós-modernismo, com Featherstone, como o aumento crescente do consumo, das atividades do consumidor, variedade das escolhas e assim por diante. Quais são as variações nesse mercado? Eu realmente não sei se esse livro teve tanto impacto. Penso além: foi importante para a elaboração de um conhecimento de que esses bens e serviços são fundamentais agora para as indústrias criativas. 0 trabalho de Angela McRobbie, por exemplo; quero dizer, tem surgido uma série de pessoas diferentes que entendem as mudanças nos mercados e na economia do capitalismo tardio. Isso sim é importante. Entender o mundo das empresas de moda no trabalho de McRobbie, por exemplo, o papel que a moda desempenha na economia. Em relação aos debates, eu realmente não segui onde e o que foi produzido após a publicação do livro. Mas temos que compreender algo: onde estão os mercados emergentes, qual é o volume de todos os tipos de cultura e estética nesses mercados. Um dos grandes avanços quando pensamos nesse tema foi feito na geografia ao se analisar o papel dessas questões no desenvolvimento de políticas e iniciativas nos níveis público e governamental. Isto se arrola à necessidade de uma política para a criação de indústrias, e é sobre dinheiro, outros valores comerciais, os tipos de bens, serviços, mercadorias para a economia, o tipo de surgimento que leva à economia estética. Outra área na qual eu suponho que essa dimensão tem se transformado em um valor é o papel que a estética desempenha em muitos mercados nos quais o trabalho estético é de fato uma parte constituinte, portanto, desde a venda de produtos, não necessariamente moda, a qualquer outro prestador de serviços, é carregado algum valor estético. Há, assim, outro grande debate sobre o papel da estética como uma maneira de vender coisas, sendo desde um produto estético, também na dimensão de algo que precisa ser portado,

\footnotetext{
${ }^{14}$ Tradução minha para: "aesthetics are not something 'added on' as a decorative feature once a product has been defined", in those markets "they are the product/s and, as such, are at the centre of the economic calculations of the practice".
} 
por exemplo, as políticas e os uniformes corporativos e as regras sobre a maneira como as pessoas têm de se vestir ou se comportar para serem empregadas. Essa necessidade de se apresentar de determinada maneira caracteriza outro tipo de momento, e foi sobre isso que eu escrevi, o trabalho estético como grande parte de um assunto econômico.

Em The aesthetic economy of fashion e também em Fashion, Latour and actor-network-theory, você, partindo dos debates já estabelecidos na teoria social, oferece-nos um modelo de análise que atualiza tais discussões ao incorporar a noção de redes de sociabilidade (actor-network) de Bruno Latour e também as ideias de Michel Callon. Quais os ganhos e as vantagens dessa metodologia para o estudo sociológico e histórico dos fenômenos na moda?

[...] Na verdade, quando eu estudei a noção das agências modernas, muito da compreensão sobre moda, sobre o sistema de moda, centrava-se nos indivíduos ou nos grupos, a maneira como essas pessoas influenciam o que somos, o que compramos ou o que é contabilizado como moda. Para mim, o grande ganho da teoria das redes de atores (ANT) caminha em duas direções. Primeiro, o requisito absoluto de seguir os atores, de observar o que as pessoas e as coisas fazem em situações que resultam em moda. Há uma insistência puramente metodológica na ANT com a qual eu concordo. Quando eu estudei os compradores de moda, esse foi o meu principal método. Eu segui os compradores de moda em todos os espaços nos quais eles faziam esses cálculos, nas reuniões, nas viagens, durante a semana de moda e os encontros com designers em estúdios, nos encontros na loja, e questionei o que era feito das mercadorias que compravam. Logo, seguir o ator é mais um método do que uma teoria; embora ele introduza todos os conceitos teóricos, é particularmente um método, esse é o primeiro ponto. Olhar e buscar o que acontece nas situações nas quais você acompanha os atores é a diferença crítica entre a ANT e outras teorias da moda. A ANT não olha apenas para os seres humanos, ela olha para as coisas, as relações entre as coisas e a situação; as agências podem ser não humanas [...]. Na verdade, quando você observa o que os compradores de moda estão fazendo, eles não calculam esses valores dentro de uma vacuidade; calculam com ferramentas, materiais e, assim, no sentido da ANT, os materiais são eles próprios agências no processo de cálculo. Portanto, ver como os compradores de moda interagem com os produtos e a maneira como tocam e sentem os tecidos, esse conjunto de fatores, produz as decisões sobre o que eles vão comprar, a forma como o tecido é sentido; a roupa torna-se uma agência. Ao observar como os compradores de moda tomam decisões sobre o que comprar, não se pode evitar perceber a maneira como as planilhas, os orçamentos do quanto gastar, os documentos sobre tendências, como tudo isso é empregado no cálculo. Não é possível contornar o fato de que esses dispositivos financeiros desempenham um papel na maneira como eles escolhem o que comprar. No acompanhamento dos produtos de volta à loja, toda semana, eles revisam as estatísticas de vendas - analisam as vendas semanais e depois as mensais -, e há um merchandising que os orienta para essa matemática, eles precisam olhar para as estatísticas financeiras para tomar decisões sobre 
o que vai ser adquirido ou quais produtos devem ser transferidos para uma loja diferente. Na verdade, esse senso de agência coloca a ideia de que, quando olhamos para esse cálculo, não estamos considerando apenas um cálculo humano - cálculos humanos são valores que vêm por meio de toda uma gama de dispositivos e ferramentas outras -, portanto, essa leitura torna-se muito importante para mim. A sociologia econômica tem insistido no tema da agência, esse cálculo que ocorre em diferentes espaços, não apenas na mente humana. Não é um tema dos mais importantes e correntes nos estudos de moda, por isso, pensei que deveríamos inscrever e incorporar algumas dessas ideias da ANT para entender a moda.

\section{Baseado nessa noção de redes de sociabilidade (actor-network),} como as ferramentas digitais (Facebook e Instagram, por exemplo), responsáveis por produzir redes em uma escala jamais conhecida, atuam na redefinição da moda e do corpo na contemporaneidade? Qual a força desse conteúdo virtualizado sobre transformações objetivas no sistema da moda e nos sujeitos que a consomem? Há, nesse sentido, mais pontos positivos ou negativos?

Existem, como mencionei anteriormente, mudanças claramente muito importantes na maneira como a moda é distribuída, disseminada e mediada. As elites - da moda - tinham o controle sobre o que comprar e o que colocar na revista. Essas pessoas mantinham um controle rígido sobre os regimes de representação na mídia, entretanto, o Facebook, o Instagram, todas as plataformas de mídia social, atualmente, colocam a capacidade de se criar outras representações da moda, outros corpos da moda. Isto está transformando a maneira como pensamos a moda e as tendências, diferentemente de quando elas eram rigorosamente controladas por essas elites e por uma noção de fluxo temporal. Coleções e pré-coleções ainda são muito controladas, existe o fluxo temporal da moda, mas a velocidade com que as tendências podem se mover é muito, muito mais rápida. Há, portanto, ainda desfiles bianuais, mas há muitas coleções sazonais no meio, até mesmo as grandes casas de moda tiveram que acelerar a entrega das tendências, uma vez que essas mudam muito rapidamente. Há um tipo de mudança puramente temporal, e esse é o resultado disso. 0 tempo da moda mudou. Acelerou. Essa é uma grande inflexão. As pessoas podem se colocar no sistema da moda. Os blogueiros de moda, nos primeiros dias da internet, conseguiram conquistar uma enorme quantidade de seguidores fora de um sistema oficial. Claramente, $o$ sistema de moda reconheceu o poder dessas pessoas que estavam localizadas fora do sistema, que não podiam falar sobre moda estando além do sistema. Agora, entretanto, eles estão na primeira fila dos desfiles. O Instagram funciona de maneira semelhante, e até mesmo de uma forma mais democrática que o blog. 0 Instagram é superinstantâneo. Um número cada vez maior de pessoas pode compartilhar e enviar suas imagens de estilos de moda. Há uma grande circulação de imagens de moda que não é mais controlado, não é mediado pelos canais regulares e legítimos, e eu reconheço que isso está mudando a maneira como pensamos um ideal de moda. 0 ideal de moda representado pelas modelos muito magras, jovens e brancas ainda está na capa das revistas, mas, agora, todos reclamam do sistema de moda e do estreitamento dessas estéticas. De fato, isso muda de forma muito lenta. Con- 
tudo, se olharmos para fora desse sistema, para o Instagram, por exemplo, encontraremos muitas comunidades de pessoas cujo corpo não está em conformidade com esse status, que estão postando imagens de seus corpos, vinculando-se a outros grupos nas mídias sociais. Lá, podemos obter ideias alternativas do corpo da moda, corpos grandes, corpos negros e assim por diante. Há uma voz mais democrática que é habilitada por essas plataformas. Entretanto, penso que há muitas perguntas que precisam ser feitas sobre esse tema e estamos apenas no começo dessas indagações, precisamos perguntar sobre a relação entre o poder e as plataformas. Há problemas nisso. A maneira como o sistema de moda está tentando incorporar os blogueiros, como estes usam o Instagram, de que forma as marcas de moda estão usando as mídias sociais, e isso nos exige alguns questionamentos. Claramente, todos postam imagens de si no Instagram, mas nem todos estão aptos para receber tantos seguidores, e nem todos trabalham com alguma marca. Precisamos pensar como a indústria da moda e as marcas de moda estão colonizando o Instagram e nos perguntar sobre com quem trabalham e com quem não trabalham. Existe, evidentemente, uma voz democrática mais poderosa, mas precisamos começar a ser críticos sobre o que realmente está acontecendo no Instagram e como o sistema de moda se envolve com ele, como o coloniza e o monetiza. Há muitas perguntas para serem feitas sobre a plataforma, o algoritmo que a controla, o que está aparecendo no feed das pessoas, como o algoritmo é curado, se há uma mão humana por trás. Existem, portanto, muitas perguntas sobre o modo como as mídias sociais e o Instagram estão mudando os debates sobre moda: aparentemente do lado de fora desse sistema, mas batendo em sua porta.

Quando você estuda maneiras especificas de vestir o corpo, como certos perfis no Instagram ou roupas indianas tradicionais, você nos apresenta um desafio para lidar com a oposição binária comumente encontrada na teoria da moda entre roupas "modernas" e "tradicionais". Como você lida com essas premissas na sua pesquisa e quais são as abordagens metodológicas de superação dessa binaridade?

Essa é certamente uma das fraquezas dos meus primeiros trabalhos, principalmente no livro The fashioned body. Foi uma fraqueza no momento que escrevi, novamente, do ponto de vista de uma socióloga europeia, não sou uma antropóloga e não estava tão familiarizada com o trabalho em antropologia. Desde então, tivemos muitos estudos fantásticos sobre os cruzamentos entre alguns trajes modernos e tradicionais [...]. Muitos antropólogos e geógrafos fizeram trabalhos nesse campo e acho que é uma binaridade difícil de sustentar nas situações contemporâneas quando se passa por essas diferentes modernidades, acho que é uma suposição, no primeiro livro, que eu suprimi em alguma medida. Se eu estivesse escrevendo The fashioned body atualmente, com certeza o escreveria de outra forma. Eu estava escrevendo a partir da ideia de que existe um tipo de modernidade europeia, e a ideia de que há um sistema de moda na Europa no qual ocorre uma mudança rápida em seu esquema de vestimentas. Uma mudança pela mudança em si [...]. Se perseguirmos essa definição de moda, reduziremos a algo que se trata de uma rápida rotatividade e de uma busca constante 
pela novidade. 0 que eu estava dizendo na época era que a forma de se pensar o vestuário é bastante peculiar ao tipo de roupa na França, ou em Londres, em um momento particular da história. Ainda é algo peculiar, mas claramente existem diferentes passagens entre o que poderíamos chamar de roupas tradicionais e roupas modernas. Evidentemente, podemos pensar em cruzamentos sociais entre trajes tradicionais e modernos; existem muitas maneiras pelas quais podemos traçar linhas claras entre esses dois tipos de moda, ambas modernas. Existem apropriações de muitas formas tradicionais de se vestir, reciclando-as constantemente, mas agora também por causa da reivindicação das comunidades que produzem em muitas ocasiões suas próprias criações. Há claramente um tipo de sistema de moda moderno que, geralmente, veste-se com roupas tradicionais - mantendo assim um ciclo de novidades -, e há também muitas adaptações de roupas tradicionais. Na Índia, por exemplo, estas estimulam toda uma indústria da moda. A binaridade está mais borrada no contemporâneo, penso que, naquele momento [o processo de escrita de The fashioned body], eu estava presa a uma definição muito estreita. Hoje, acho impossível pensarmos os trajes tradicionais como puras entidades culturais. São entidades evidentemente hibridizadas.

\section{Agradecimentos}

Os entrevistadores agradecem à presidência da Abepem (Kathia Castilho e Maria de Fátima Mattos) e do 15o Colóquio de Moda (Cyntia Tavares) 